\title{
Glial Cell Inhibition of Neurons by Release of ATP
}

\author{
Eric A. Newman \\ Department of Neuroscience, University of Minnesota, Minneapolis, Minnesota 55455
}

\begin{abstract}
ATP is released by neurons and functions as a neurotransmitter and modulator in the CNS. Here I show that ATP released from glial cells can also serve as a potent neuromodulator, inhibiting neurons in the retina of the rat. Activation of glial cells by focal ejection of ATP, ATP $\gamma \mathrm{S}$, dopamine, thrombin, or lysophosphatidic acid or by mechanical stimulation evoked hyperpolarizing responses and outward currents in a subset of retinal ganglion cells by increasing a $\mathrm{Ba}^{2+}$-sensitive $\mathrm{K}^{+}$conductance in the neurons. This glia-evoked inhibition reduced the firing rate of those neurons that displayed spontaneous spike activity. The inhibition was abolished by the $A_{1}$ adenosine receptor antagonist DPCPX (8-cyclopentyl-1,3-dipropylxanthine) (10 nM) and was reduced by the ecto-ATPase inhibitor ARL-67156 (6- $N, N$-diethyl-D- $\beta, \gamma$-dibromomethyleneATP) (50 $\mu \mathrm{M})$ and by the ectonucleotidase inhibitor AOPCP [adenosine-5' - 0 - $(\alpha, \beta$-methylene)diphosphonate] $(250 \mu \mathrm{M})$. Selective activation of retinal glial cells demonstrated that Müller cells, but not astrocytes, mediate the inhibition. ATP release from Müller cells into the inner plexiform layer of the retina was shown using the luciferin-luciferase chemiluminescence assay. These findings demonstrate that activated glial cells can inhibit neurons in the retina by the release of ATP, which is converted to adenosine by ectoenzymes and subsequently activates neuronal adenosine receptors. The results lend support to the hypothesis that glial cells play an active role in information processing in the CNS.
\end{abstract}

Key words: astrocyte; Müller cell; glial cell; ganglion cell; retina; ATP; adenosine; modulation; inhibition

\section{Introduction}

Glial cells have traditionally been viewed as passive elements in the CNS, providing structural and metabolic support to neurons but playing little role in information processing. Recent studies have demonstrated, however, that glial cells may directly modulate neuronal activity by releasing neuroactive substances. In both glial-neuronal cocultures (Hassinger et al., 1995; Araque et al., 1998a,b) and in intact tissue preparations (Pasti et al., 1997; Newman and Zahs, 1998; Castonguay and Robitaille, 2001), activated glial cells have been shown to depolarize neurons and to modulate transmitter release from presynaptic terminals. In some of these systems, glial modulation of neuronal activity is believed to be mediated by the release of glutamate from glial cells (Araque et al., 2001; Haydon, 2001; Vesce et al., 2001). It has been suggested, but not yet demonstrated, that glial cells may also modulate neuronal activity by releasing ATP (Cotrina et al., 2000; Newman, 2001b).

ATP, when released from neurons, functions as a neurotransmitter and neuromodulator. ATP is coreleased with classical neurotransmitters at neuronal synapses, where it activates purinergic receptors (Zimmermann, 1994). ATP released at synapses is also metabolized extracellularly to adenosine, which is a potent inhibitory neuromodulator, increasing postsynaptic $\mathrm{K}^{+}$conductance and decreasing presynaptic $\mathrm{Ca}^{2+}$ conductance (Trussell and Jackson, 1985; Gerber et al., 1989; Greene and Haas, 1991; Zimmermann, 1994; Cunha, 2001).

Neurons have traditionally been considered to be the sole source of neuromodulatory ATP and adenosine in the CNS. Re-

\footnotetext{
Received 0ct. 17, 2002; revised Dec. 6, 2002; accepted Dec. 9, 2002.

This work was supported by National Institutes of Health Grant EY04077. I thank H. C. Lee for purification of ATP $\gamma$ S, P. Ceelen for technical assistance, and J. I. Gepner, K. R. Zahs, and R. F. Miller for helpful discussions.

Correspondence should be addressed to Dr. Eric A. Newman, Department of Neuroscience, University of Minnesota, 6-145 Jackson Hall, 321 Church Street Southeast, Minneapolis, MN 55455. E-mail: ean@umn.edu. Copyright $\odot 2003$ Society for Neuroscience $\quad 0270-6474 / 03 / 231659-08 \$ 15.00 / 0$
}

cently, however, glial cells have also been shown to release ATP (Cotrina et al., 1998; Wang et al., 2000; Newman, 2001b), raising the possibility that glial cells might modulate neuronal activity by activating purinergic receptors.

We have demonstrated previously that activated glial cells can either excite or inhibit the light-evoked spike activity of neurons in the mammalian retina (Newman and Zahs, 1998). Here I show that activation of glial cells in the retina leads to the release of ATP from glial cells, the activation of neuronal adenosine receptors, and the generation of an inhibitory response in retinal neurons. The results demonstrate that, in addition to the glutamate-release mechanism described previously, glial cells can actively modulate neuronal activity by releasing ATP.

\section{Materials and Methods}

Recording procedures. Recordings were made from whole-mount retinas of male Long-Evans rats (250-400 gm). Retinas were enzymatically treated with collagenase-dispase and DNase and the vitreous was removed, as described previously (Newman and Zahs, 1998). Retinas were superfused at 2-3 $\mathrm{ml} / \mathrm{min}$ in HEPES-buffered Ringer's solution. Except when otherwise noted, experiments were conducted at $24^{\circ} \mathrm{C}$. The animals used in this study were treated in accordance with the guidelines of the Institutional Animal Care and Use Committee of the University of Minnesota (Minneapolis, MN).

Whole-cell recordings were made from neuronal somata in the ganglion cell layer of the retina, viewed with infrared differential interference contrast (IR-DIC) optics (BX60 microscope, $40 \times 0.8$ numerical aperture objective; Olympus, Tokyo, Japan). Patch pipettes (see Fig. 1a) were lowered into the ganglion cell layer, and pipette solution was expelled to blow away glial cell processes surrounding a cell soma. Suction was then applied to obtain a high-resistance seal. Whole-cell current-clamp and voltage-clamp recordings were made with a MultiClamp 700A amplifier (Axon Instruments, Union City, CA). Voltage-clamp holding potentials were set to the cell resting membrane potential. Cell voltage was corrected for the pipette junction potential (JPCalc-pClamp software; Axon Instruments), which equaled $10 \mathrm{mV}$.

Neuronal morphology was characterized by filling cells with Lucifer 
yellow $\mathrm{CH}$ contained in the patch pipette. After recording from a neuron, the Lucifer yellow-filled cell was viewed with confocal microscopy using $458 \mathrm{~nm}$ excitation and a $500 \mathrm{~nm}$ long-pass barrier filter.

The depth of the deepest dendrites of a neuron was determined from confocal fluorescence and IR-DIC observations made on the live retina immediately after recording from the neuron. The depths of the inner surface of the retina and the inner and outer borders of the inner plexiform layer (IPL) were determined from IR-DIC observations. [The inner and outer borders of the IPL were distinguished using the adjacent somata of the ganglion cell and inner nuclear layers as landmarks.] The depth of the deepest (outermost) dendrites of the neuron was determined from confocal observations of the Lucifer yellow-filled cell. The location of the deepest dendrites was then expressed as a percentage of the total depth of the IPL.

Glial cells were activated by ejecting agonists mixed in Ringer's solution from a pipette (1-2 $\mu \mathrm{m}$ tip diameter; $17 \mathrm{psi}$ ) (see Fig. $1 \mathrm{~b}$ ) onto the inner surface of the retina. The agonist concentrations specified are the concentrations within the pipette. Concentrations at the retinal surface after ejection were lower because of dilution. Astrocyte somata were also stimulated mechanically, with the tip of a patch pipette moved sinusoidally at $5 \mathrm{~Hz}$ and $15-20 \mu \mathrm{m}$ peak-to-peak amplitude.

Calcium imaging. Retinas were incubated in the $\mathrm{Ca}^{2+}$-indicator dye Fluo-4 AM $(21 \mu \mathrm{g} / \mathrm{ml})$ and pluronic acid $(2.6 \mathrm{mg} / \mathrm{ml})$ for $25 \mathrm{~min}$ at room temperature, as described previously (Newman, 2001b). Dye incubation filled astrocytes and Müller cells but did not fill retinal neurons. Indicator dye fluorescence was monitored with $488 \mathrm{~nm}$ excitation, a $500 \mathrm{~nm}$ longpass barrier filter, and confocal microscopy (Odyssey scanner; Noran, Middleton, WI). Glial $\mathrm{Ca}^{2+}$ changes and neuronal responses were recorded simultaneously.

ATP imaging. ATP release from glial cells was detected using the luciferin-luciferase chemiluminescence assay, as described previously (Newman, 2001b). When imaging ATP release from the retinal surface, retinas were bathed in Ringer's solution containing luciferin and luciferase. Glial cells at the retinal surface were stimulated mechanically, and the resulting chemiluminescence signal was measured at the surface.

When imaging ATP release within the inner plexiform layer (see Fig. 1c), a small volume of Ringer's solution containing luciferin and luciferase was pressure-ejected from a pipette into this retinal layer. The luciferin-luciferase solution was ejected into the retina $5 \mathrm{sec}$ before mechanical stimulation of glial cells at the retinal surface. The ATP chemiluminescence signal detected after glial stimulation always occurred near the luciferin-luciferase ejection site within the inner plexiform layer.

For both experiments, the luciferin-luciferase solution contained 70 $\mu \mathrm{l}$ of luciferase stock solution (L-1759; Sigma, St. Louis, MO; $10 \mathrm{mg} / \mathrm{ml}$ in $0.5 \mathrm{M}$ Tris buffer, $\mathrm{pH} 7.6$ ) and $70 \mu \mathrm{l}$ of luciferin stock solution (L-6882; Sigma; $11.1 \mathrm{mg} / \mathrm{ml}$ in $\mathrm{H}_{2} \mathrm{O}$ ) per milliliter of HEPES Ringer's solution. ATP chemiluminescence was detected with an intensified, cooled CCD camera (I-PentaMAX; Roper Scientific, Trenton, NJ) using an integration time of $1 \mathrm{sec}$ and $2 \times 2$ binning.

Solutions. The HEPES-buffered Ringer's solution contained (in $\mathrm{mM}$ ): 135.5 NaCl, 3.0 KCl, 2.0 $\mathrm{CaCl}_{2}, 1.0 \mathrm{MgSO}_{4}, 0.5 \mathrm{NaH}_{2} \mathrm{PO}_{4}, 15.0 \mathrm{D}$-glucose, and 10 HEPES, $\mathrm{pH} 7.44$, equilibrated with $100 \% \mathrm{O}_{2}$. The intracellular pipette solution contained (in $\mathrm{mM}$ ): $5.0 \mathrm{Na}$-methanesulfonate, 128.0 K-methanesulfonate, 2.0 $\mathrm{MgCl}_{2}$, 5.0 K-EGTA, 1.0 glutathione, 2.0 MgATP, $0.2 \mathrm{NaGTP}$, and 5.0 HEPES, pH 7.4. In some experiments, $0.005 \%$ Lucifer yellow $\mathrm{CH}$ was added to the pipette solution to characterize neuronal morphology.

ATP $\gamma S$ was purified by HPLC using an AG MP-1 column and a gradient of trifluoroacetic acid. Reagents were purchased from Sigma, except for 2,3dihydroxy-6-nitro-7-sulfonyl-benzo[f] quinoxaline (NBQX), DL-AP-7, bicuculline, saclofen, scopolamine, and 8-cyclopentyl-1,3-dipropylxanthine (DPCPX), which were purchased from Tocris (Ellisville, MO).

Statistics. Numerical values are given as mean \pm SEM. Statistical significance was determined by the Student's $t$ test (paired samples).

\section{Results}

\section{Glial cell activation inhibits neurons}

Glial cell modulation of neurons was studied in whole mounts of the rat retina. Astrocytes and Müller cells, the two macroglial cells

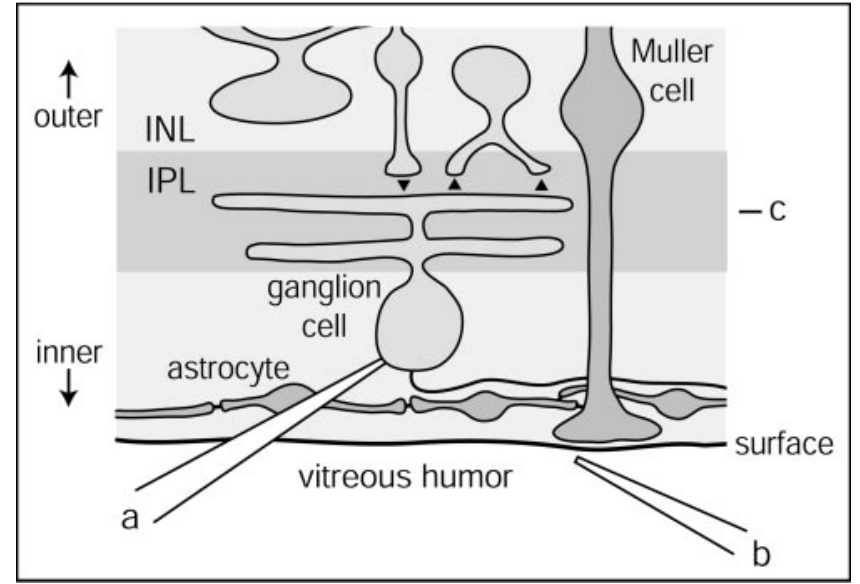

Figure 1. Recording configuration and cells of the inner retina. Shown are the two macroglial cells of the mammalian retina, astrocytes (restricted to the inner border of the retina), and radial Müller cells (extended throughout the depth of the retina). Also shown is the whole-cell recording pipette $(a)$, the agonist ejection pipette $(b)$, the level at which ATP release was monitored $(c)$, the inner nuclear layer (INL), and the IPL. Triangles represent synapses.

of the retina (Fig. 1) (Newman, 2001a), were stimulated by pressure-ejecting agonists onto the inner retinal surface. Glial cell responses to the ejections were monitored by measuring changes in intracellular glial $\mathrm{Ca}^{2+}$ with a $\mathrm{Ca}^{2+}$ indicator dye and confocal microscopy. Responses of neurons to glial cell stimulation were monitored in whole-cell voltage- and current-clamp recordings.

Ejection of agonists onto the retinal surface often evoked $\mathrm{Ca}^{2+}$ increases in astrocytes and Müller cells. Glial cells displaying such $\mathrm{Ca}^{2+}$ increases are referred to as being activated. The physiological consequences of activating glial cells are not completely understood, although glial release of glutamate (Araque et al., 2001; Haydon, 2001; Vesce et al., 2001) and ATP (Cotrina et al., 1998; Wang et al., 2000; Newman, 2001b) is associated with glial activation. Activation of retinal glial cells does not necessarily result in changes in glial cell membrane potential or membrane conductance (Newman and Zahs, 1997).

Ejection of a number of agonists, including ATP $(100 \mu \mathrm{M})$, ATP $\gamma$ S (a nonhydrolyzable ATP analog; $100 \mu \mathrm{M}$ ), dopamine (1 or $2 \mathrm{~mm})$, thrombin $(100 \mathrm{U} / \mathrm{ml})$, and lysophosphatidic acid (LPA) $(500 \mu \mathrm{M})$, as well as mechanical stimulation of astrocyte somata, evoked $\mathrm{Ca}^{2+}$ increases in both astrocytes and Müller cells, as reported previously (Biedermann et al., 1995; Puro and Stuenkel, 1995; Manning and Sontheimer, 1997; Newman and Zahs, 1997; Newman, 2001b). These stimuli also evoked hyperpolarizing responses and the generation of outward currents in a subset of neurons (Fig. $2 A-C$ ).

Of the 138 neurons studied, $35.5 \%$ showed little or no hyperpolarization $(<0.2 \mathrm{mV}), 52.2 \%$ showed moderate hyperpolarizations $(0.2-5 \mathrm{mV})$, and $12.3 \%$ showed large hyperpolarizations $(>5 \mathrm{mV})$. Neuronal hyperpolarization was slow, peaking at $6.0 \pm$ $0.2 \mathrm{sec}$ and lasting for $19.2 \pm 0.8 \mathrm{sec}(n=31)$, when evoked by brief ejection of agonist solution (0.2-2 sec duration).

Regardless of the stimulus used to activate the glial cells, the time course of the neuronal response closely followed increases in glial $\mathrm{Ca}^{2+}$ (Fig. $2 \mathrm{~A}-\mathrm{C}$ ), suggesting that the response was evoked by glial cells rather than directly by the stimulus. This correlation was particularly clear in neurons in which two different stimuli were used to activate the glial cells. In the experiment illustrated in Figure $2 C$, for instance, the glial $\mathrm{Ca}^{2+}$ increase elicited by mechanical stimulation peaked later and was more prolonged 

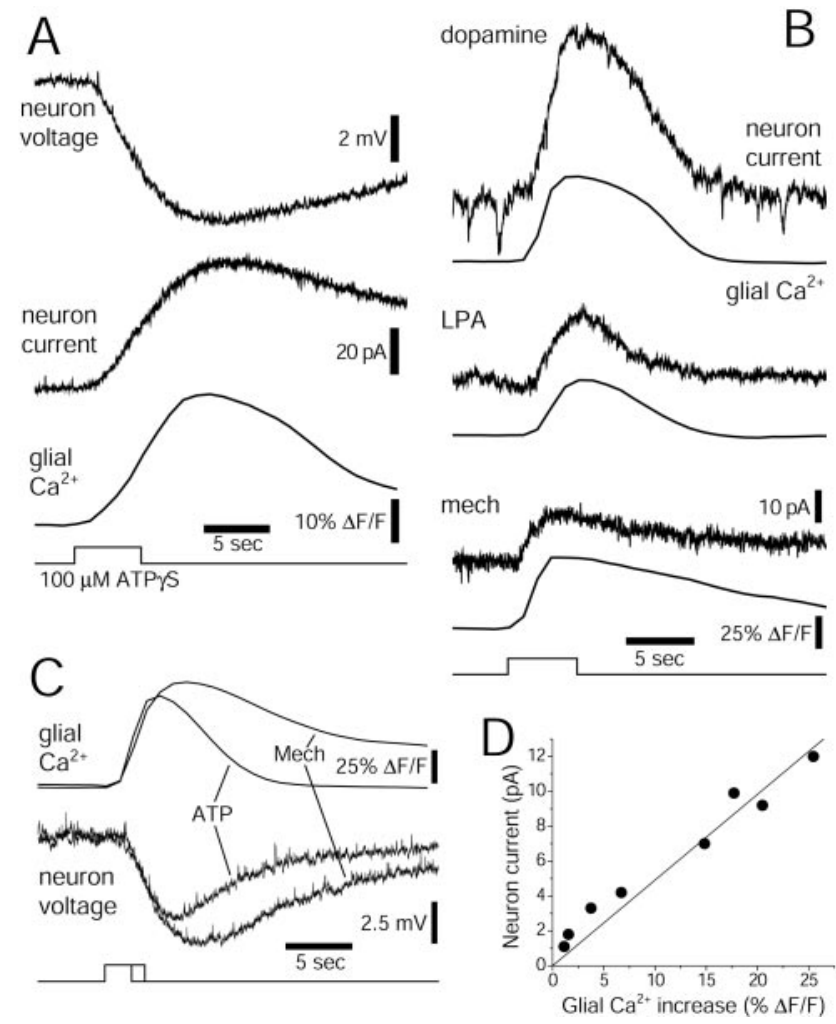

Figure 2. Inhibitory neuronal responses are evoked by glial cell stimulation. A, Glial cell activation by ATP $\gamma S$ ejection elicits a $\mathrm{Ca}^{2+}$ increase in glial cells and evokes a hyperpolarization and the generation of an outward current in a neuron. The voltage and current traces were recorded in sequential trials from the same neuron. Resting membrane potential and holding potential are $-72 \mathrm{mV}$. B, Activation of glial cells by ejection of $1 \mathrm{~mm}$ dopamine and $500 \mu \mathrm{mLPA}$ and by mechanical (mech) stimulation all evoke $\mathrm{Ca}^{2+}$ increases in glial cells and the generation of an outward current in neurons. Records are from three different neurons. Holding potential, $-61,-74$, and $-71 \mathrm{mV}$, respectively. C, Activation of glial cells by agonist ejection (100 $\mu \mathrm{m}$ ATP; 2 sec duration) and mechanical (Mech) stimulation ( 3 sec duration) both elicit hyperpolarization in a neuron. For each stimulus, the time course of the glial $\mathrm{Ca}^{2+}$ response and the neuronal hyperpolarization closely match each other. The two sets of records were recorded in consecutive trials from the same neuron. Resting membrane potential, $-72 \mathrm{mV}$. D, Relationship between outward neuronal currents and glial $\mathrm{Ca}^{2+}$ increases recorded in consecutive trials on a single neuron. The relationship is fit by least squares (correlation coefficient, $r=0.99$ ). Glial cells were activated by $100 \mu \mathrm{m}$ ATP $\gamma S$ ejections of varying duration ( $10 \mathrm{msec}$ to $2 \mathrm{sec}$ ). Glial $\mathrm{Ca}^{2+}$ increases were measured from Müller cell processes in the inner plexiform layer (Fig. 1c).

than was the $\mathrm{Ca}^{2+}$ increase elicited by ATP ejection. The time course of the resulting hyperpolarizations in the neuron followed these glial $\mathrm{Ca}^{2+}$ increases closely.

There was a close correlation between the amplitude of glial $\mathrm{Ca}^{2+}$ responses and neuronal inhibitory responses as well. The amplitude of the outward current evoked in a given neuron increased linearly as the amplitude of the glial $\mathrm{Ca}^{2+}$ response increased (Fig. 2D). Inhibitory responses were not evoked when agonist ejection failed to elicit a glial $\mathrm{Ca}^{2+}$ response. The correlation between glial $\mathrm{Ca}^{2+}$ increases and neuronal current was best when glial $\mathrm{Ca}^{2+}$ responses were measured in Müller cells within the inner plexiform layer (Fig. 1c). The correlation coefficient of the glial $\mathrm{Ca}^{2+}$-neuronal current relationship, $r$, equaled $0.92 \pm$ $0.04(n=4)$.

Most experiments were conducted at $24^{\circ} \mathrm{C}$, because higher temperatures caused retinal preparations to deteriorate quickly and resulted in rapid fading of Fluo-4 labeling in glial cells. However, a series of experiments were conducted at $35^{\circ} \mathrm{C}$ to determine whether the inhibitory neuronal responses observed at $24^{\circ} \mathrm{C}$ were
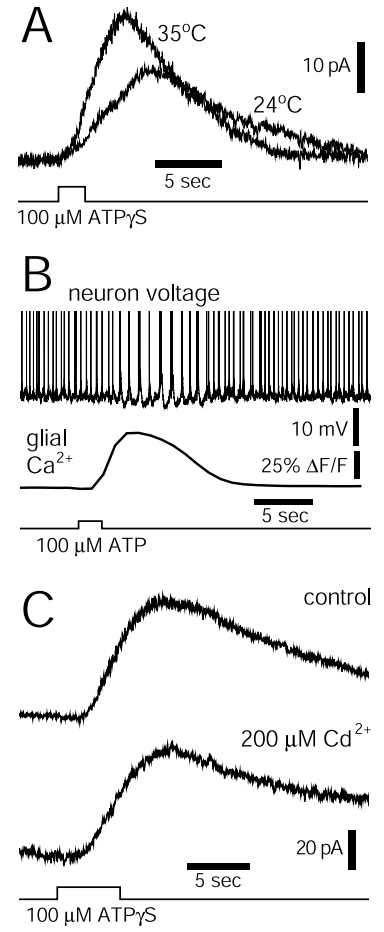

Figure 3. Properties of the inhibitory neuronal response. $A$, Raising the temperature of the retina from 24 to $35^{\circ} \mathrm{C}$ resulted in a glial-evoked outward current that was larger in amplitude and had a faster time course. The two responses were recorded in consecutive trials on the same neuron. Holding potential, $-76 \mathrm{mV}$. $B$, The spontaneous spike activity of a neuron was inhibited when glial cells were activated by agonist ejection. The glial-evoked hyperpolarization in the neuron was $1.7 \mathrm{mV}$. The action potentials (vertical lines in the neuron voltage record) have been truncated. Resting membrane potential, $-63 \mathrm{mV}$. C, The outward current generated in a neuron in response to glial cell activation was not reduced when synaptic transmission was blocked with $\mathrm{Cd}^{2+}$. Holding potential, $-76 \mathrm{mV}$.

also evoked at a temperature close to that present in vivo. Raising the temperature from 24 to $35^{\circ} \mathrm{C}$ resulted in glial-evoked outward currents in neurons that were larger in amplitude and had a faster time course (Fig. 3A). Mean current amplitude increased $72 \pm$ $18 \%(n=8 ; p<0.001)$, and latency to the peak of the current decreased from 7.2 to $5.2 \sec (n=8 ; p<0.001)$ when the temperature was increased from 24 to $35^{\circ} \mathrm{C}$.

Neuronal hyperpolarizations evoked by activating glial cells resulted in a reduction in the frequency of action potential generation in those neurons that displayed spontaneous spike activity. Even small glial-evoked hyperpolarizations (1-2 mV) decreased neuronal spike frequency (Fig. $3 B$ ).

The glial-evoked inhibitory neuronal responses described above could be mediated by a direct inhibitory action of glial cells on the neurons or indirectly by glial cell excitation of amacrine cells, which inhibit ganglion cells in the retina. To distinguish between these two possibilities, synaptic signaling between neurons was blocked by addition of $\mathrm{Cd}^{2+}$, which blocks synaptic transmission onto ganglion cells in the retina (Chen and Diamond, 2002). Addition of $200 \mu \mathrm{M} \mathrm{Cd}^{2+}$ to the superfusate did not reduce the outward current generated in the neurons (122 \pm $10 \%$ of control; $n=10$ ) (Fig. $3 C$ ), demonstrating that activation of inhibitory interneurons was not responsible for glial cellmediated neuronal inhibition.

\section{Morphological characterization of neurons}

The morphology of the neurons studied was characterized by filling cells with Lucifer yellow. Within the ganglion cell layer, all 

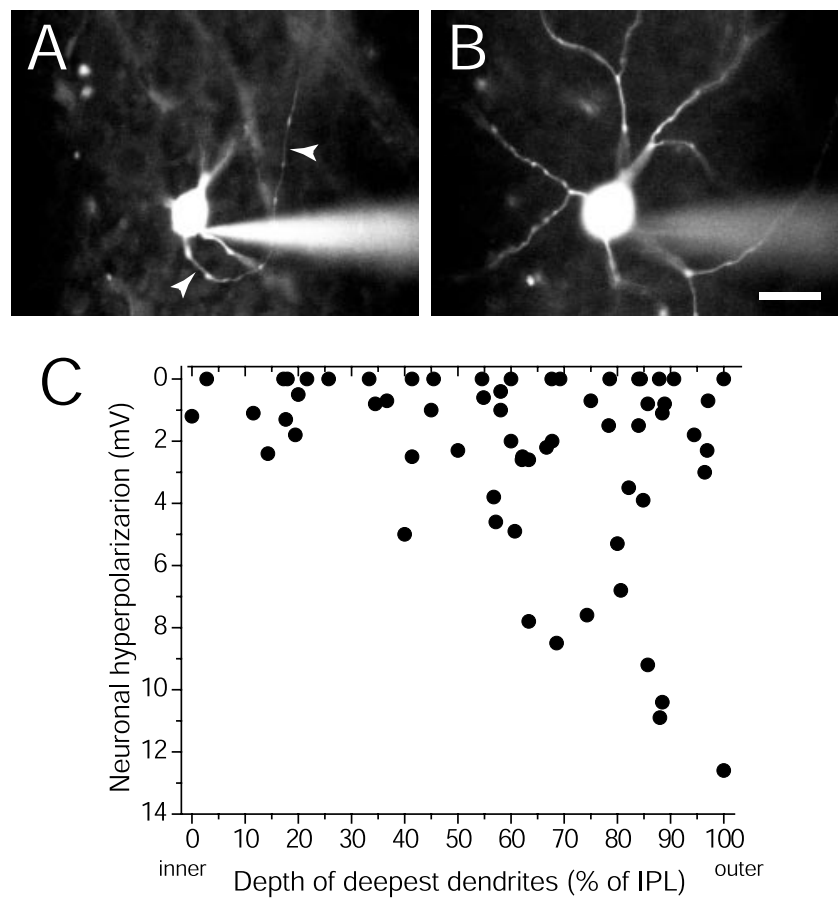

Figure 4. Relationship between neuronal inhibition and dendritic depth. $A, B$, Confocal micrographs of a Lucifer yellow-filled neuron. $A$, Eight micrometers below the retinal surface, at the level of the cell soma. Arrowheads indicate the axon of the neuron. The recording pipette is shown to the right. $B$, Eighteen micrometers below the retinal surface. The deepest dendrites of the neuron in $A$, as well as the out-of-focus soma are shown. Scale bar, $25 \mu \mathrm{m}$. C, Relationship between glial-evoked neuronal hyperpolarization and the depth of the deepest dendrites of neurons. Each filled circle represents a single neuron. The absolute depths of the inner and outer borders of the IPL differed for each cell studied. Mean depths corresponding to 0 and $100 \%$ of the IPL equaled 18 and $49 \mu \mathrm{m}$, measured from the inner surface of the retina.

filled neurons with somata $>10 \mu \mathrm{m}$ in diameter had axons (Fig. $4 A$ ), demonstrating that they were ganglion cells rather than displaced amacrine cells, which are present in the ganglion cell layer of the rat retina (Perry and Walker, 1980). All neurons characterized in this study were ganglion cells.

There was a correlation between the amplitude of the inhibitory responses of the neurons characterized and the depth to which their dendrites extended (Fig. 4B). The largest inhibitory responses were recorded from neurons whose dendrites extended deep into the outer portion of the inner plexiform layer. This relationship is revealed in a plot of neuronal hyperpolarization evoked by glial cell activation, graphed as a function of the depth of the deepest dendrites of the neuron (Fig. 4C). This relationship shows that the deeper the dendrites of a neuron extend into the IPL, the greater the inhibitory response of the neuron can be. The plot also demonstrates, however, that many neurons show little or no inhibition, even when their dendrites extend deep into the outer IPL.

\section{Müller glial cells inhibit neurons}

The stimuli used to activate glial cells produced $\mathrm{Ca}^{2+}$ increases in both astrocytes and Müller cells, and either of these glial cells could be responsible for generating inhibitory responses in the neurons. Astrocytes and Müller cells were selectively activated to determine which was responsible for inhibiting the neurons. I have demonstrated previously that $\mathrm{Ca}^{2+}$ waves do not propagate between astrocytes and Müller cells by diffusion of an intracellular messenger but rather by the release of ATP, and that selective
A Surface ejection

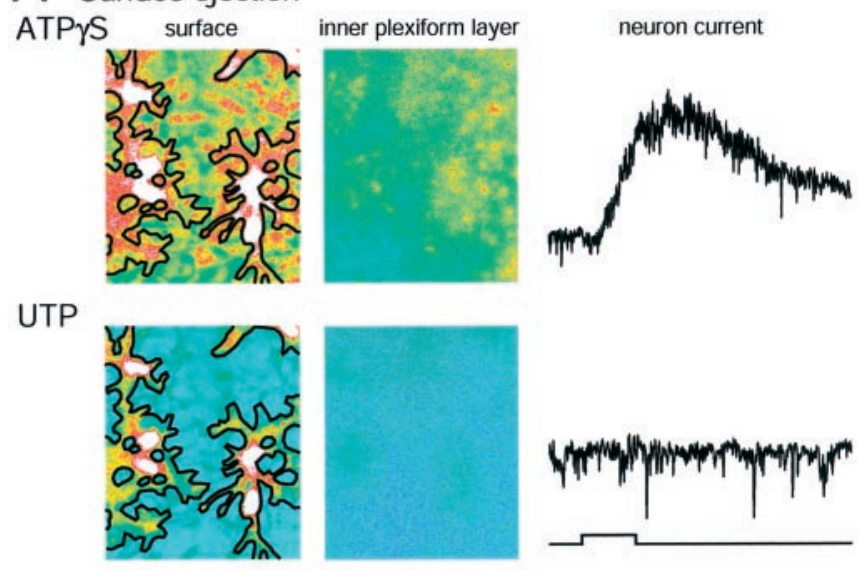

B Inner nuclear layer ejection

ATP $\gamma \mathrm{S}$
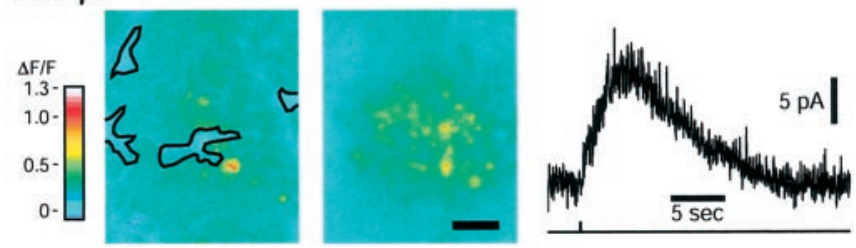

Figure 5. Müller glial cells evoke neuronal inhibition. Shown for each trial are two pseudocolor $\mathrm{Ca}^{2+}$ ratio images and a record of neuronal current. The image on the left shows $\mathrm{Ca}^{2+}$ changes at the retinal surface, reflecting $\mathrm{Ca}^{2+}$ in both astrocytes (outlined by black lines) and Müller cells (outside these black lines). The image in the middle indicates $\mathrm{Ca}^{2+}$ changes in the inner plexiform layer (Fig. 1C), reflecting $\mathrm{Ca}^{2+}$ changes in Müller cells. A, ATP $\gamma 5(100 \mu \mathrm{M})$ ejected onto the retinal surface activates both astrocytes and Müller cells and evokes an outward current in a neuron. UTP (100 $\mu \mathrm{m})$ ejection activates astrocytes but not Müller cells and fails to evoke a current. The $\mathrm{Ca}^{2+}$ images and current records were acquired in four consecutive trials on the same neuron. The neuron currents and the corresponding inner plexiform layer $\mathrm{Ca}^{2+}$ images were acquired simultaneously. Holding potential, $-76 \mathrm{mV}$. B, ATP $\gamma \mathrm{S}(100 \mu \mathrm{M})$ ejection into the inner nuclear layer activates Müller cells but not astrocytes and evokes an outward current in a neuron in a different preparation from $A$. The neuron current and inner plexiform layer $\mathrm{Ca}^{2+}$ image were acquired simultaneously. Holding potential, $-73 \mathrm{mV}$. The pseudocolor scale at the bottom left indicates $\mathrm{Ca}^{2+}$ ratio values. Scale bar , $25 \mu \mathrm{m}$.

activation of either type of glial cell can be achieved by limiting the strength of the stimulus (Newman, 2001b).

UTP ejection onto the retinal surface was effective in activating astrocytes but much less effective in activating Müller cells. When $100 \mu \mathrm{M}$ UTP was ejected and failed to evoke $\mathrm{Ca}^{2+}$ increases in Müller cells, indicating that Müller cells were not activated, outward currents were not observed in neurons $(n=6)$ (Fig. 5A, UTP). When ATP $\gamma \mathrm{S}$ was ejected at the same site, activating both Müller cells and astrocytes, outward currents were recorded from the same neurons $(n=6)$ (Fig. $5 A, A T P \gamma S)$.

In complementary experiments, when $\mathrm{ATP} \gamma \mathrm{S}$ was ejected into the inner nuclear layer, activating Müller cells but not astrocytes, outward currents were observed in neurons $(n=6)$ (Fig. $5 B)$. These results demonstrate that activation of Müller cells, but not astrocytes, is both necessary and sufficient to evoke neuronal inhibitory responses.

Neuronal adenosine receptor activation

The nature of the glial transmitter evoking neuronal inhibition was investigated in pharmacological experiments. Antagonists to AMPA (10 $\mu \mathrm{M}$ NBQX), NMDA (100 $\mu \mathrm{M}$ DL-AP-7), GABA ${ }_{\mathrm{A}}(5 \mu \mathrm{M}$ 


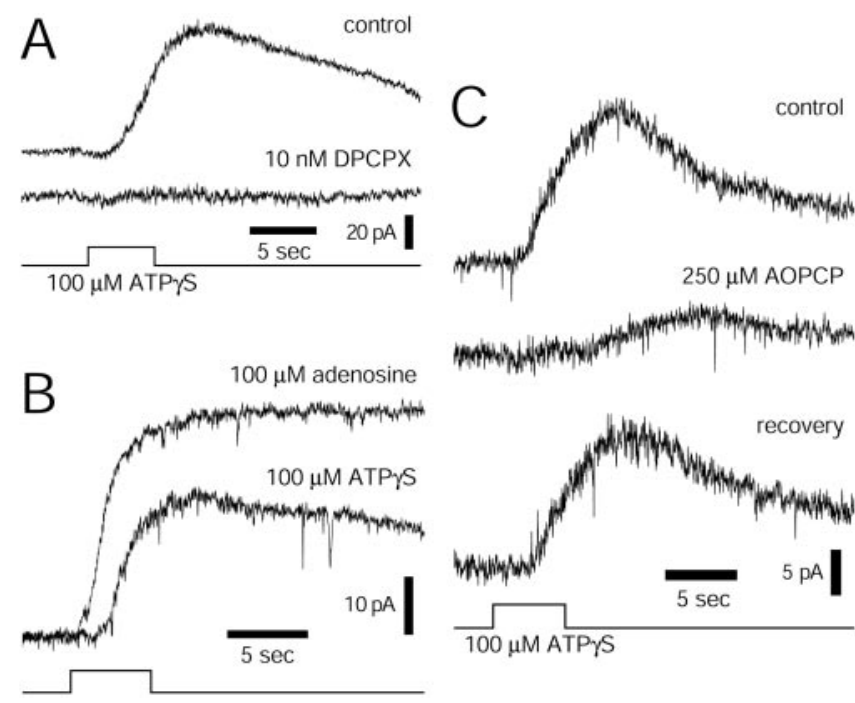

Figure 6. $A_{1}$ adenosine receptor activation evokes neuronal inhibition. $A$, The $A_{1}$ adenosine receptor antagonist DPCPX abolishes the outward neuronal current evoked by glial cell activation. Holding potential, $-71 \mathrm{mV}$. B, Adenosine ejection evokes a larger, shorter-latency neuronal current than does ATP $\gamma S$ ejection at the same retinal location and with the same neuron. Holding potential, $-76 \mathrm{mV}$. C, The ectonucleotidase inhibitor AOPCP reduces and slows the time course of the neuronal current. The effect is largely reversible. Recovery time, $11 \mathrm{~min}$. Holding potential, $-75 \mathrm{mV}$.

bicuculline), $\mathrm{GABA}_{\mathrm{B}}(200 \mu \mathrm{M}$ saclofen), glycine (1 $\mu \mathrm{M}$ strychnine), and muscarinic (10 $\mu \mathrm{M}$ scopolamine) receptors, when added to the superfusate, did not substantially reduce glia-evoked outward currents in neurons. In contrast, the $A_{1}$ adenosine receptor antagonist DPCPX (Cunha et al., 1998; Huang et al., 1999), when added to the superfusate, completely blocked outward currents at low concentrations (Fig. 6A). When glial cells were activated by ATP $\gamma \mathrm{S}$ or ATP, outward current amplitude was reduced to $1.1 \pm 0.8 \%$ of control $(n=13 ; p<0.005)$ by $10 \mathrm{nM}$ DPCPX. Similarly, when glial cells were activated by $2 \mathrm{~mm}$ dopamine, outward currents were reduced to $1.0 \pm 1.0 \%$ of control $(n=7 ; p<0.005)$ by $10 \mathrm{~nm}$ DPCPX. These results indicate that glial cells inhibit neurons by stimulating neuronal adenosine receptors.

I hypothesized that the source of the inhibitory adenosine was ATP released from Müller cells and hydrolyzed to adenosine in extracellular space. Release of ATP from glial cells has been demonstrated in a number of in vitro and in situ systems (Cotrina et al., 1998; Wang et al., 2000; Newman, 2001b). Released ATP would be rapidly metabolized to adenosine by ecto-ATPases and ectonucleotidases, leading to the activation of neuronal adenosine receptors, which are present on ganglion cells (Braas et al., 1987; Kvanta et al., 1997; Zhang and Schmidt, 1999).

This hypothesis was supported by a number of findings. Direct activation of neuronal adenosine receptors by ejection of adenosine evoked outward currents in ganglion cells. The adenosine-evoked currents, although not statistically different in amplitude ( $132 \pm 23 \% ; n=8 ; p>0.05)$, had shorter latencies $(0.61 \pm 0.18 \mathrm{sec}$ vs $1.51 \pm 0.18 \mathrm{sec} ; n=8 ; p<0.005)$ than the currents evoked by ATP $\gamma \mathrm{S}$ ejection (Fig. $6 \mathrm{~B}$ ). The outward currents evoked by adenosine ejection were not significantly reduced by $200 \mu \mathrm{M} \mathrm{Cd}^{2+}$ ( $85 \pm 6 \%$ of control; $n=4 ; p>0.05$ ), demonstrating that the currents resulted from direct stimulation of ganglion cells rather than from stimulation of interneurons.

ATP, when released into extracellular space, is metabolized rapidly ( $\sim 200 \mathrm{msec})$ from ATP to ADP to AMP to adenosine

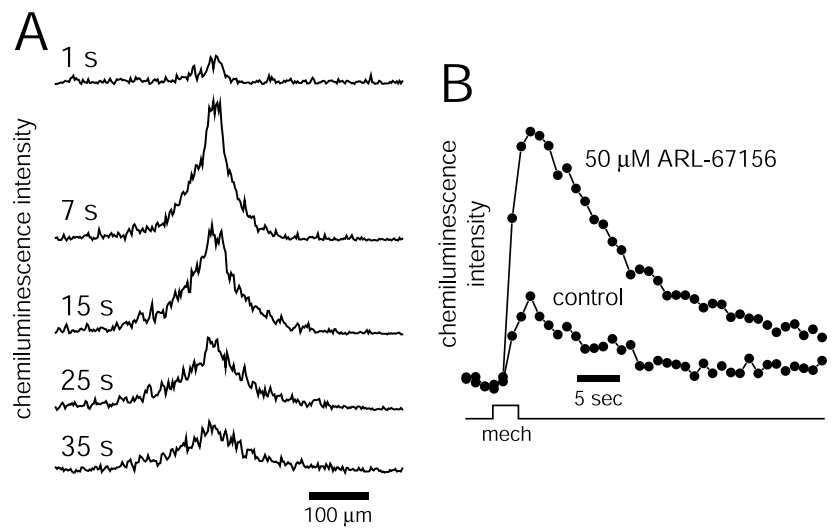

Figure 7. Release of ATP from glial cells. A, Mechanical stimulation of glial cells at the retinal surface evokes ATP release at the surface, detected by the luciferin-luciferase chemiluminescence assay. The five line-scans show the spatial pattern of chemiluminescence in a line passing through the stimulation site at the indicated times after stimulation. $B$, ATP release into the inner plexiform layer. A small volume of luciferin-luciferase solution was ejected from a pipette into the IPL, $5 \mathrm{sec}$ before mechanical stimulation of glial cells at the retinal surface. The traces show the chemiluminescence signal recorded near the ejection pipette tip in the IPL (Fig. 1C) and are averages of five trials. Addition of the ecto-ATPase inhibitor ARL-67156 increases the chemiluminescence signal. A $100 \mu \mathrm{m}$ concentration of $\mathrm{Cd}^{2+}$ was present in the superfusate in both $A$ and $B$ to block $\mathrm{Ca}^{2+}$-dependent transmitter release from neurons.

(Zimmermann, 1994; Dunwiddle et al., 1997; Cunha et al., 1998). If glial inhibition of neurons results from the release of ATP, then interfering with this metabolic cascade should block the inhibition. Addition of $50 \mu \mathrm{M}$ 6- $N, N$-diethyl-D- $\beta, \gamma$-dibromomethyleneATP (ARL-67156) to the superfusate, an ecto-ATPase inhibitor that prevents conversion of ATP to ADP (Westfall et al., 1996), resulted in a reduction of neuronal outward current to $47 \pm 7 \%$ of control $(n=$ $5 ; p<0.05)$. Similarly, addition of $250 \mu \mathrm{M}$ adenosine-5'-O- $(\alpha, \beta-$ methylene)-diphosphonate (AOPCP), an ectonucleotidase inhibitor that prevents conversion of AMP to adenosine (Kreutzberg et al., 1978; Kreutzberg and Hussain, 1982; Cunha et al., 1998), reduced outward currents to $35 \pm 3 \%$ of control $(n=6 ; p<0.001)$ (Fig. $6 C$ ). Both inhibitors slowed the time course of the outward currents and were partially reversible. The results support the hypothesis that glial cells inhibit neurons by releasing ATP that is subsequently metabolized to adenosine.

\section{ATP release from Müller cells}

I have shown previously using the luciferin-luciferase chemiluminescence assay that glial cell stimulation results in the release of ATP from the surface of the retina (Newman, 2001b). In that study, glial cells were the likely source of the released ATP. However, ATP release from neurons could not be ruled out. I have now repeated this experiment in the presence of $100 \mu \mathrm{M} \mathrm{Cd}^{2+}$, which blocks $\mathrm{Ca}^{2+}$-dependent release of ATP from neurons. With $\mathrm{Cd}^{2+}$ added to the superfusate, mechanical stimulation of glial cells evoked a chemiluminescence signal that spread outward from the point of stimulation (Fig. 7A). The presence of the ATP-induced chemiluminescence signal after addition of $\mathrm{Cd}^{2+}$ strengthens the conclusion that ATP release in these experiments comes from glial cells rather than from neurons.

The experiment described above indicates that activated glial cells release ATP at the surface of the retina. The luciferin-luciferase assay was also used to demonstrate that Müller glial cells release ATP directly into the inner plexiform layer. Instead of bathing the entire retina in luciferin-luciferase solution, as was done to demonstrate ATP release at the retinal surface, a small volume of luciferin-luciferase Ringer's solution was ejected di- 


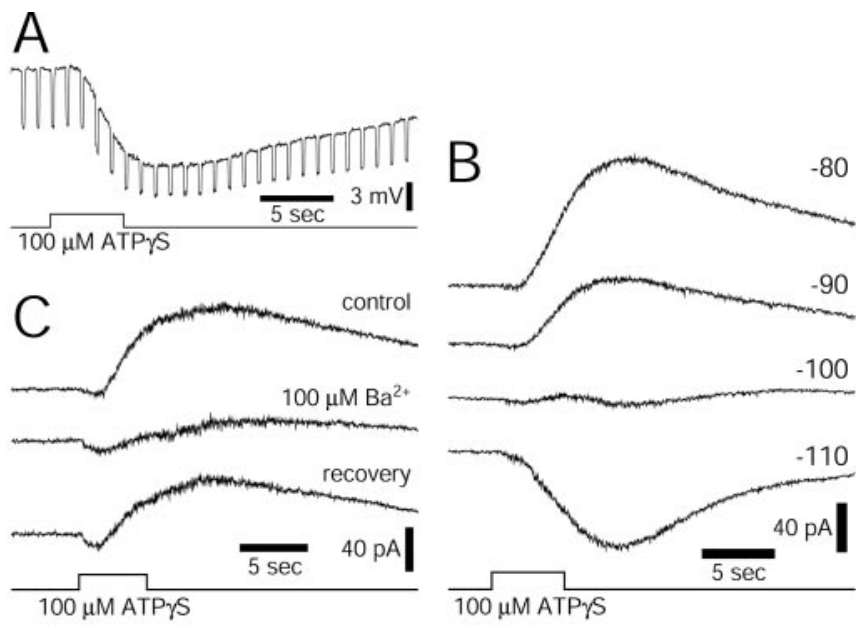

Figure 8. Glial-evoked neuronal inhibition is generated by the opening of $\mathrm{Ba}^{2+}$-sensitive $\mathrm{K}^{+}$channels. $A$, Neuronal hyperpolarization is accompanied by a decrease in cell input resistance. Responses to $-32 \mathrm{pA}$ current pulses injected into a neuron are reduced during the hyperpolarization. Resting potential, $-83 \mathrm{mV}$. $B$, Reversal potential of the current generating the hyperpolarization is $-98 \mathrm{mV}$ in this neuron, near the $\mathrm{K}^{+}$equilibrium potential. Holding potentials are given to the right. $C$, The $\mathrm{K}^{+}$channel blocker $\mathrm{Ba}^{2+}$ reduces the neuronal current evoked by glial cell activation. The effect is largely reversible. Recovery time, $6 \mathrm{~min}$. Holding potential, $-72 \mathrm{mV}$.

rectly into the IPL. Using this protocol, only ATP release into the IPL would result in a chemiluminescence signal. Experiments were conducted in the presence of $100 \mu \mathrm{M} \mathrm{Cd}^{2+}$ to block $\mathrm{Ca}^{2+}$ dependent release of ATP from neurons.

When glial cells at the surface of the retina were stimulated mechanically, a chemiluminescence signal was observed near the tip of the luciferin-luciferase ejection pipette (Fig. 7B). Addition of the ecto-ATPase inhibitor ARL-67156 (50 $\mu \mathrm{M})$ to the superfusate substantially increased the chemiluminescence signal by preventing the rapid hydrolysis of ATP. In control experiments, ejection of the luciferin-luciferase solution without glial cell stimulation did not produce a chemiluminescence signal. The results confirm that activation of glial cells results in the release of ATP into the IPL.

\section{Neuronal $\mathrm{K}^{+}$conductance increase}

The mechanism by which adenosine receptor activation results in the generation of inhibitory neuronal responses was also studied. Neuronal hyperpolarization evoked by glial cell activation was accompanied by a decrease in cell input resistance (Fig. $8 \mathrm{~A}$ ), indicating that inhibition is mediated by an opening of ion channels. The reversal potential of the outward current generating the hyperpolarization was $-93 \pm 2 \mathrm{mV}(n=4)$ (Fig. $8 B$ ). This value is close to the calculated $\mathrm{K}^{+}$equilibrium potential of $-97 \mathrm{mV}$, suggesting that $\mathrm{K}^{+}$channels open during inhibition. Addition of the $\mathrm{K}^{+}$channel blocker $\mathrm{Ba}^{2+}(100 \mu \mathrm{M})$ to the superfusate reduced the inhibition (outward current or hyperpolarization) to $28 \pm 12 \%(n=10 ; p<0.05)$ of control amplitude (Fig. $8 C)$. The $\mathrm{Ba}^{2+}$ effect was largely reversible.

In contrast, the outward current was unaffected by changes in the $\mathrm{Cl}^{-}$gradient across neurons. Substitution of methanesulfonate for $\mathrm{Cl}^{-}$in the superfusate solution did not reduce neuronal hyperpolarization ( $111 \pm 19 \%$ of control; $n=6$ ), demonstrating that $\mathrm{Cl}^{-}$-permeable channels do not mediate the inhibition.

The results demonstrate that ganglion cell inhibition is generated by the opening of $\mathrm{Ba}^{2+}$-sensitive $\mathrm{K}^{+}$channels. $\mathrm{A}_{1}$ receptor activation leads to a similar $\mathrm{K}^{+}$conductance increase in many types of neurons by stimulating $\mathrm{G}_{\mathrm{i}} / \mathrm{G}_{\mathrm{o}}$ proteins and opening $\mathrm{Ba}^{2+}$-sensitive, G-protein-coupled inwardly rectifying $\mathrm{K}^{+}$channels (Trussell and Jackson, 1985, 1987; Gerber et al., 1989; Greene and Haas, 1991; Zimmermann, 1994; Mark and Herlitze, 2000; Cunha, 2001). The glial-evoked inhibition of retinal ganglion cells observed in this study is most likely mediated by G-proteincoupled inwardly rectifying $\mathrm{K}^{+}$channels as well.

\section{Discussion}

\section{Glial inhibition of neurons in the retina}

The results demonstrate that activated glial cells can evoke inhibitory responses in retinal neurons by the release of ATP and the subsequent activation of neuronal adenosine receptors. Several lines of evidence support this conclusion. Stimulation of glial cells by a number of agonists results in the inhibition of retinal ganglion cells. Ganglion cell inhibition is also evoked when a distant astrocyte is stimulated mechanically. Neuronal inhibition is blocked by the $A_{1}$ adenosine receptor antagonist DPCPX. Inhibition is also reduced by the ecto-ATPase inhibitor ARL-67156 and the ectonucleotidase inhibitor AOPCP, demonstrating that the source of the inhibitory adenosine is the hydrolysis of ATP released into extracellular space. In addition, ATP imaging using the luciferin-luciferase chemiluminescence assay demonstrates that stimulation of glial cells results in the release of ATP into the inner plexiform layer.

The source of the ATP that mediates neuronal inhibition is almost certainly glial rather than neuronal, as demonstrated by the following findings: (1) Glial-induced inhibition of neurons is not reduced by addition of $\mathrm{Cd}^{2+}$, which blocks $\mathrm{Ca}^{2+}$-dependent release of ATP from neurons. ATP release from glial cells, in contrast, is believed to be $\mathrm{Ca}^{2+}$ independent (Wang et al., 2000) (E. A. Newman, unpublished observations) and, as demonstrated here, is not blocked by $\mathrm{Cd}^{2+}$. (2) A number of different stimuli (ATP, ATP $\gamma \mathrm{S}$, dopamine, thrombin, LPA, mechanical stimulation) all activate glial cells and are all effective in evoking neuronal inhibition. It is unlikely that all of these stimuli also evoke a prolonged release of ATP (lasting many seconds) from neurons. [ATP, used as a stimulus to activate glial cells in the present experiments, could directly inhibit neurons after its conversion to adenosine. The primary effect of ejected ATP is to activate glial cells rather than to directly inhibit neurons, however, because the time courses of neuronal inhibition in response to ejected ATP and ejected ATP $\gamma \mathrm{S}$ are similar. Presumably, little of the ATP that is ejected onto the retinal surface is converted to adenosine, and of this adenosine, little diffuses into the inner plexiform layer before being removed by uptake systems (Cunha et al., 1998).] (3) The time course of neuronal inhibitory responses closely follows the time course of $\mathrm{Ca}^{2+}$ increases in glial cells, suggesting a direct relationship between glial cell activation and neuronal inhibition. [The precise timing between a glial $\mathrm{Ca}^{2+}$ response and a neuronal inhibitory response is influenced by a number of factors. ATP release from glial cells is believed to be $\mathrm{Ca}^{2+}$ independent (Wang et al., 2000) and may actually precede the glial $\mathrm{Ca}^{2+}$ increase (Newman, 2001b). This will have the effect of advancing the neuronal response with respect to the glial response. On the other hand, the delay introduced by the conversion of ATP to adenosine and the delay inherent in second messenger system activation of neuronal $\mathrm{K}^{+}$channels will retard the neuronal response with respect to the glial response.] (4) The amplitude of neuronal inhibitory responses is closely correlated to the magnitude of glial $\mathrm{Ca}^{2+}$ increases, also suggesting a direct relationship between glial cell activation and neuronal inhibition.

The results demonstrate that, of the two types of macroglial 
cells in the retina, Müller cells, rather than astrocytes, evoke inhibitory neuronal responses. Selective activation of each type of glial cell reveals that activation of Müller cells is both necessary and sufficient to evoke neuronal inhibition. This is not surprising, because neuronal inhibition occurs in the inner plexiform layer (the synaptic layer of retinal ganglion cells). Müller cells, but not astrocytes, are present in this retinal layer.

Morphological analysis demonstrates that neurons whose dendrites extend deep into the inner plexiform layer display larger inhibitory responses than do cells with more superficial dendrites. Thus, OFF ganglion cells, whose dendrites ramify in the outer half of the IPL, are more likely to be inhibited by glial cells than are ON ganglion cells. Localization of glial inhibition of neurons to the outer portion of the IPL could arise for several reasons, including the following: (1) Müller cells may release ATP selectively into this region, (2) the activity of the ectoenzymes that convert ATP to adenosine may be higher in this region, or (3) $\mathrm{A}_{1}$ adenosine receptors or the $\mathrm{K}^{+}$channels that generate the inhibition may be present at higher densities on the dendrites of ganglion cells in the outer portion of the inner plexiform layer.

Of the neurons characterized, 35\% showed little or no inhibition by glial cells, whereas $12 \%$ showed large hyperpolarizations $(>5 \mathrm{mV})$. This indicates that glial inhibition of neurons in the retina is not a global, indiscriminant phenomenon, but rather represents a selective interaction between glial cells and a subset of neurons. As discussed above, ganglion cells responding to the OFF of light are more likely to be inhibited by glial cells than are ON ganglion cells.

Glial cell inhibition of neurons can be substantial. In our preparation, $12 \%$ of the neurons studied showed hyperpolarizations of $>5 \mathrm{mV}$ and lasting tens of seconds. These hyperpolarizations can have a large inhibitory effect on the spike activity of ganglion cells. As demonstrated by recordings from neurons displaying spontaneous spike activity, even small glial-evoked hyperpolarizations $(1-2 \mathrm{mV})$ can substantially inhibit the firing rate of neurons. Experiments performed at $35^{\circ} \mathrm{C}$ indicate that glial-evoked inhibitory responses in neurons will be even larger at body temperature than at $24^{\circ} \mathrm{C}$, the temperature at which most experiments were conducted.

We have shown previously that activation of glial cells can inhibit light-evoked spike activity in retinal ganglion cells (Newman and Zahs, 1998). In these previous experiments, inhibition of spike activity was blocked by antagonists to glutamate, GABA, and glycine receptors. In the present work, in contrast, these antagonists were ineffective in blocking glial inhibition of neurons. It is likely, therefore, that the mechanism of glial inhibition of neurons described here, the release of ATP and activation of neuronal adenosine receptors, is not responsible for the inhibition of light-evoked spike activity observed previously. This suggests that a second mechanism of glial inhibition of neurons, perhaps inhibiting the release of neurotransmitters from presynaptic terminals, may also be present in the retina. Presynaptic inhibition could be mediated by the release of either ATP (Cunha, 2001) or glutamate (Araque et al., 1998a) from Müller cells. The existence of a glial-evoked presynaptic inhibition is supported by preliminary observations that indicate that spontaneous and evoked EPSCs recorded in ganglion cells are reduced when glial cells are activated. Glial inhibition of transmitter release from presynaptic terminals has been observed previously in glial-neuronal cocultures (Araque et al., 1998a). The experiments conducted in the present study would not have detected glial-mediated presynaptic inhibition.

It remains to be established to what degree glial cells inhibit neuronal activity in the retina in vivo and what role this inhibition plays in the processing of visual information. It is not known, for instance, whether light-evoked neuronal activity activates glial cells in the retina. Preliminary experiments indicate that spontaneous $\mathrm{Ca}^{2+}$ oscillations occur in retinal Müller cells (Newman, 2002). These $\mathrm{Ca}^{2+}$ increases may be associated with ATP release and could result in neuronal inhibition in vivo.

\section{Glial inhibition of neurons in the brain}

The ATP-release mechanism of neuronal inhibition described here may operate throughout the CNS. Application of neurotransmitters (Finkbeiner, 1993), as well as electrical stimulation of neurons (Jahromi et al., 1992; Porter and McCarthy, 1996; Pasti et al., 1997; Grosche et al., 1999; Araque et al., 2002), results in the activation of astrocytes, the principal glial cells of the brain. Astrocyte activation, in turn, results in ATP release (Cotrina et al., 1998; Wang et al., 2000; Newman, 2001b). The subsequent breakdown of glial-released ATP to adenosine could have widespread modulatory effects on neuronal activity, because adenosine is a potent inhibitory neuromodulator in the brain (Trussell and Jackson, 1985; Gerber et al., 1989; Greene and Haas, 1991; Zimmermann, 1994; Cunha, 2001).

Indeed, the results of a previous report (Cunha et al., 1998) suggest that glial cells may inhibit neurons in the hippocampus. Application of ATP $\gamma S$ and other nonhydrolyzable ATP analogs in this preparation inhibited neurons through activation of $A_{1}$ receptors. This inhibition was attributed to residual hydrolysis of these nonhydrolyzable analogs to adenosine. It is more likely, however, that the ATP analogs stimulated hippocampal glial cells, which, in turn, released ATP that was then hydrolyzed to adenosine. Thus, the mechanism of glial inhibition of neurons described in the present study may also be responsible for neuronal inhibition in the hippocampus.

Glial cells have been shown previously to modulate neuronal activity through the release of glutamate (Kang et al., 1998; Araque et al., 2001; Haydon, 2001; Vesce et al., 2001). Our results now demonstrate that glial cells can modulate neuronal activity through a second, independent mechanism, the release of ATP. Together, these findings lend support to the hypothesis that glial cells play an active role in information processing in the brain. In addition, adenosine has been shown to modulate several forms of synaptic plasticity, including long-term potentiation (Huang et al., 1999) and depression (de Mendonca and Ribeiro, 1997), raising the possibility that glial cells, through the release of ATP, may participate in the regulation of learning and memory.

\section{References}

Araque A, Parpura V, Sanzgiri RP, Haydon PG (1998a) Glutamatedependent astrocyte modulation of synaptic transmission between cultured hippocampal neurons. Eur J Neurosci 10:2129-2142.

Araque A, Sanzgiri RP, Parpura V, Haydon PG (1998b) Calcium elevation in astrocytes causes an NMDA receptor-dependent increase in the frequency of miniature synaptic currents in cultured hippocampal neurons. J Neurosci 18:6822-6829.

Araque A, Carmignoto G, Haydon PG (2001) Dynamic signaling between astrocytes and neurons. Annu Rev Physiol 63:795-813.

Araque A, Martin ED, Perea G, Arellano JI, Buno W (2002) Synaptically released acetylcholine evokes $\mathrm{Ca}^{2+}$ elevations in astrocytes in hippocampal slices. J Neurosci 22:2443-2450.

Biedermann B, Frohlich E, Grosche J, Wagner H-J, Reichenbach A (1995) Mammalian Müller (glial) cells express functional $\mathrm{D}_{2}$ dopamine receptors. NeuroReport 6:609-612.

Braas KM, Zarbin MA, Snyder SH (1987) Endogenous adenosine and adenosine receptors localizes to ganglion cells of the retina. Proc Natl Acad Sci USA 84:3906-3910. 
Castonguay A, Robitaille R (2001) Differential regulation of transmitter release by presynaptic and glial $\mathrm{Ca}^{2+}$ internal stores at the neuromuscular synapse. J Neurosci 21:1911-1922.

Chen S, Diamond JS (2002) Synaptically released glutamate activates extrasynaptic NMDA receptors on cells in the ganglion cell layer of rat retina. J Neurosci 22:2165-2173.

Cotrina ML, Lin JHC, Alves-Rodriques A, Liu S, Li J, Azmi-Ghadimi H, Kang J, Naus CCG, Nedergaard M (1998) Connexins regulate calcium signaling by controlling ATP release. Proc Natl Acad Sci USA 95:15735-15740.

Cotrina ML, Lin JH-C, Lopez-Garcia JC, Naus CCG, Nedergaard M (2000) ATP-mediated glia signaling. J Neurosci 20:2835-2844.

Cunha RA (2001) Adenosine as a neuromodulator and as a homeostatic regulator in the nervous system: different roles, different sources and different receptors. Neurochem Int 38:107-125.

Cunha RA, Sebastiao AM, Ribeiro JA (1998) Inhibition by ATP of hippocampal synaptic transmission requires localized extracellular catabolism by ecto-nucleotidases into adenosine and channeling to adenosine A1 receptors. J Neurosci 18:1987-1995.

de Mendonca A, Ribeiro JA (1997) Adenosine and neuronal plasticity. Life Sci 60:245-251.

Dunwiddle TV, Diao L, Proctor WR (1997) Adenine nucleotides undergo rapid, quantitative conversation to adenosine in the extracellular space in rat hippocampus. J Neurosci 17:7673-7682.

Finkbeiner SM (1993) Glial calcium. Glia 9:83-104.

Gerber U, Greene RW, Haas HL, Stevens DR (1989) Characterization of inhibition mediated by adenosine in the hippocampus of the rat in vitro. J Physiol (Lond) 417:567-578.

Greene RW, Haas HL (1991) The electrophysiology of adenosine in the mammalian central nervous system. Prog Neurobiol 36:329-341.

Grosche J, Matyash V, Moller T, Verkhratsky A, Reichenbach A, Kettenmann H (1999) Microdomains for neuron-glia interaction: parallel fiber signaling to Bergmann glial cells. Nat Neurosci 2:139-143.

Hassinger TD, Atkinson PB, Strecker GJ, Whalen LR, Dudek FE, Kossel AH, Kater SB (1995) Evidence for glutamate-mediated activation of hippocampal neurons by glial calcium waves. J Neurobiol 28:159-170.

Haydon PG (2001) Glia: listening and talking to the synapse. Nat Neurosci 2:185-193.

Huang C-C, Liang Y-C, Hsu K-S (1999) A role for extracellular adenosine in time-dependent reversal of long-term potentiation by low-frequency stimulation at hippocampal CA1 synapses. J Neurosci 19:9728-9738.

Jahromi BS, Robitaille R, Charlton MP (1992) Transmitter release increases intracellular calcium in perisynaptic Schwann cells in situ. Neuron 8:1069-1077.

Kang J, Goldman SA, Nedergaard M (1998) Astrocyte-mediated potentiation of inhibitory synaptic transmission. Nat Neurosci 1:683-692.

Kreutzberg GW, Hussain ST (1982) Cytochemical heterogeneity of the glial plasma membrane: $5^{\prime}$-nucleotidase in retinal Müller cells. J Neurocytol $11: 53-64$
Kreutzberg GW, Barron KD, Schubert P (1978) Cytochemical localization of 5' -nucleotidase in glial plasma membranes. Brain Res 158:247-257.

Kvanta A, Seregard S, Sejersen S, Kull B, Fredholm BB (1997) Location of adenosine receptor messenger RNAs in the rat eye. Exp Eye Res 65:595-602.

Manning Jr TJ, Sontheimer H (1997) Bovine serum albumin and lysophosphatidic acid stimulate calcium mobilization and reversal of cAMPinduced stellation in rat spinal cord astrocytes. Glia 20:163-172.

Mark MD, Herlitze S (2000) G-protein mediated gating of inward-rectifier $\mathrm{K}^{+}$channels. Eur J Biochem 267:5830-5836.

Newman EA (2001a) Glia of the retina. In: Retina (Ryan SJ, ed), pp 89-103. St. Louis: Mosby.

Newman EA (2001b) Propagation of intercellular calcium waves in retinal astrocytes and Müller cells. J Neurosci 21:2215-2223.

Newman EA (2002) Calcium signaling in retinal glial cells and its effect on neuronal activity. Prog Brain Res 132:241-254.

Newman EA, Zahs KR (1997) Calcium waves in retinal glial cells. Science 275:844-847.

Newman EA, Zahs KR (1998) Modulation of neuronal activity by glial cells in the retina. J Neurosci 18:4022-4028.

Pasti L, Volterra A, Pozzan T, Carmignoto G (1997) Intracellular calcium oscillations in astrocytes: a highly plastic, bidirectional form of communication between neurons and astrocytes in situ. J Neurosci 17:7817-7830.

Perry VH, Walker M (1980) Amacrine cells, displaced amacrine cells and interplexiform cells in the retina of the rat. Proc R Soc Lond B Biol Sci 208:415-431.

Porter JT, McCarthy KD (1996) Hippocampal astrocytes in situ respond to glutamate released from synaptic terminals. J Neurosci 16:5073-5081.

Puro DG, Stuenkel EL (1995) Thrombin-induced inhibition of potassium currents in human retinal glial (Müller) cells. J Physiol (Lond) 485:337-348.

Trussell LO, Jackson MB (1985) Adenosine-activated potassium conductance in cultured striatal neurons. Proc Natl Acad Sci USA 82:4857-4861.

Trussell LO, Jackson MB (1987) Dependence of an adenosine-activated potassium current on a GTP-binding protein in mammalian central neurons. J Neurosci 7:3306-3316.

Vesce S, Bezzi P, Volterra A (2001) Synaptic transmission with the glia News Physiol Sci 16:178-184.

Wang Z, Haydon PG, Yeung ES (2000) Direct observation of calciumindependent intercellular ATP signaling in astrocytes. Anal Chem 72:2001-2007.

Westfall TD, Kennedy C, Sneddon P (1996) Enhancement of sympathetic purinergic neurotransmission in the guinea-pig isolated vas deferens by the novel ecto-ATPase inhibitor ARL 67156. Br J Pharmacol 117:867-872.

Zhang C, Schmidt JT (1999) Adenosine Al and class II metabotropic glutamate receptors mediate shared presynaptic inhibition of retinotectal transmission. J Neurophysiol 82:2947-2955.

Zimmermann H (1994) Signaling via ATP in the nervous system. Trends Neurosci 17:420-426. 